\title{
O FINANCIAMENTO DO PLANO NACIONAL DE EDUCAÇÃO EM DISCUSSÃO
}

\author{
Leandro Vitoriano da Silva ${ }^{1}$, Maria Eliza Nogueira Oliveira ${ }^{2}$ \\ ${ }^{1}$ Mestrando em Educação pela Universidade do Oeste Paulista (UNOESTE), Presidente Prudente, SP. Diretor de Escola na Prefeitura Municipal de \\ Rubiácea, Professor Universitário da União Cultural e Educacional de Angeles, Araçatuba, SP. E-mail: leovitoriano@hotmail.com \\ ${ }^{2}$ Doutora em Educação pelo Programa de Pós-Graduação em Educação da Universidade Estadual Paulista (UNESP), campus de Marília. Docente do \\ Mestrado em Educação da Universidade do Oeste Paulista (UNOESTE), Presidente Prudente, SP.
}

\section{RESUMO}

O novo PNE aprovado recentemente traz impactos imediatos diretos à gestão educacional por suas audaciosas metas e estratégias que visam a melhoria da educação em todos níveis e modalidades de ensino, entretanto, não fica explicitado de forma clara como se dará o financiamento deste planejamento. O objetivo deste estudo foi demonstrar a evolução do FUNDEB e do Salário Educação em comparação com o IPCA, o PSPN e número de matrículas de acordo com dados oficiais no período pós aprovação do PNE. Trata-se de uma pesquisa que adota uma abordagem quali-quantitativa, cujo método se baseia em uma Análise Documental do banco de dados do Governo Federal (MEC, FNDE e INEP). Os resultados foram agrupados em tabelas para melhor compreensão. Conclui-se que o atual modelo de financiamento da educação no Brasil, principalmente, em se tratando do FUNDEB e Salário Educação não serão suficientes para o cumprimento do previsto no PNE.

Palavras-chave: Plano Nacional de Educação, Financiamento, Gestão, FUNDEB, Salário Educação.

\section{THE FINANCING OF THE NATIONAL EDUCATION PLAN IN DISCUSSION}

\begin{abstract}
The recently approved new PNE has immediate direct impacts on educational management due to its audacious goals and strategies aimed at improving education at all levels and modalities of teaching, however, it is not made clear how funding will be given for this planning. The objective of this study was to demonstrate the evolution of FUNDEB and Education Salary in comparison with the IPCA, the PSPN and the number of enrollments according to official data in the period after approval of the PNE. It is a research that adopts a qualitative-quantitative approach, whose method is based on a Documentary Analysis of the database of the Federal Government (MEC, FNDE and INEP). The results were grouped in tables for better understanding. It is concluded that the current model of financing of education in Brazil, mainly in the case of FUNDEB and Education Salary, will not be enough to fulfill the PNE.
\end{abstract}

Keywords: National Plan for Education, Financing, Management, FUNDEB, Education Salary.

\section{INTRODUÇÃO}

O novo Plano Nacional de Educação PNE (2014-2024), aprovado após longa tramitação no congresso nacional e, ainda, trazendo em seu escopo os debates das CONAEs ${ }^{1}$, apresenta à sociedade metas audaciosas a serem alcançadas através de estratégias específicas, conforme constante na Lei 13.005/2014 que regulamenta o plano.

\footnotetext{
${ }^{1}$ As Conferências Nacionais de Educação ocorreram em 2010 e 2014, ambas com a Temática "Plano Nacional de Educação" e "A Construção do Sistema Nacional de Educação"
}

Nas 20 metas dispostas no PNE, ressaltam-se os direitos de acesso e permanência à escola, com qualidade e equidade, a inclusão, a diversidade, a valorização dos profissionais da educação com piso salarial nacional, os planos de carreira e a gestão democrática. Embora todos os direitos elencados acima já façam parte de outros dispositivos legais, eles não estão garantidos, demonstrando a insuficiência do dispositivo legal, diante da ausência de vontade política e, principalmente, condições de financiamento que garantam a consolidação das políticas públicas educacionais. 
No Brasil, devido ao federalismo cooperativo - caracterizado por formas de ações conjuntas entre as diferentes instâncias de governo -, a União, os Estados e Municípios partilham entre si a competência na oferta da Educação Básica e do Ensino Superior, com diferentes graus de participação (MARTINS, 2016). Evidencia-se que, apesar de ser elemento fundamental para a efetivação do novo PNE, o regime de colaboração entre os entes federados está prejudicado, pois a descentralização de competências não vem sendo acompanhada da descentralização de recursos, resultando na dependência de muitos municípios dos recursos oriundos da União, conforme Oliveira (2007, p.86) ressalta:

A maioria dos municípios
brasileiros seria
financeiramente inviável,
comorasfera
administrativa autônoma,
caso não recebesse as
transferências de recursos
de outras esferas. Como
regra, a grande maioria
dos municípios brasileiros
arrecada, através de
impostos próprios, menos
de 10\% de sua receita
total. Mais de 90\% de suas
receitas provém das
transferências de outras
esferas, o que explica em
muito a relação de
dependência política de
prefeitos de pequenas
cidades em relação ao
governo estadual e
federal.

É importante ressaltar que a própria lei do PNE regula, em seu artigo 8o, que os estados, o distrito federal e os municípios deverão elaborar seus planos alinhando-os ao plano nacional, de modo que as metas e estratégias nele apresentadas sejam traduzidas em políticas públicas passíveis de execução nos diferentes territórios. Todavia, para que isso ocorra de forma efetiva, é necessária a transposição de barreiras, como a barreira político-partidária e a financeira, de onde advém a importância da ação da União junto aos demais entes federados.

Ante ao exposto, torna-se necessário ampliar a discussão em torno do financiamento das metas do PNE, principalmente daquelas que competem aos municípios, e as formas como a União tem realizado as ações de redistribuição dos recursos, em especial o FUNDEB ${ }^{2}$ (Fundo de Manutenção e Desenvolvimento da Educação Básica e Valorização dos Profissionais da Educação) e o Salário Educação ${ }^{3}$ (Quota Salário Educação), bem como, os programas suplementares específicos da união como alimentação e transporte (destaca-se no âmbito federal o Programa Nacional de Alimentação Escolar - PNAE e o Programa Nacional de Apoio ao Transporte do Escolar - PNATE).

\section{METODOLOGIA}

Trata-se de uma pesquisa que adota uma abordagem quali-quantitativa, cujo método se baseia em uma Análise Documental do banco de dados do Governo Federal, disponibilizados nos sítios do Ministério da Educação, do Fundo Nacional de Desenvolvimento da Educação, e do Instituto Nacional de Estudos e Pesquisas Educacionais Anísio Teixeira.

Após o levantamento dos documentos pertinentes ao estudo, realizou-se uma leitura comparativa em que se destacaram os dados que demonstram a evolução das transferências financeiras de natureza redistributiva (FUNDEB) em comparação com a evolução das despesas através da inflação anual medida pelo Índice Nacional de Preços ao Consumidor Amplo (IPCA/IBGE) e com o Piso Salarial Profissional Nacional dos Profissionais do Magistério Público de Educação Básica (Lei 11.738/2008) - PSPN, bem como, a evolução percentual do Salário Educação (ou quota salário educação - QSE), em comparação com o efetivo aumento das matrículas na Educação Básica obrigatória, de forma a perceber se, após aprovação do PNE, os dispêndios financeiros tem garantido as

\footnotetext{
${ }^{2}$ Fundo especial, de natureza contábil e de âmbito estadual (um fundo por estado e Distrito Federal, num total de vinte e sete fundos), formado, na quase totalidade, por recursos provenientes dos impostos e transferências dos estados, Distrito Federal e municípios, vinculados à educação por força do disposto no art. 212 da Constituição Federal. Além desses recursos, ainda compõe o Fundeb, a título de complementação, uma parcela de recursos federais, sempre que, no âmbito de cada Estado, seu valor por aluno não alcançar o mínimo definido nacionalmente. Disponível em: http://www.fnde.gov.br/financiamento/fundeb/fundebapresentacao. Acesso em: 20 de fevereiro de 2017.

3 Em 1964 é criado o Salário-Educação, por meio da Lei no $4.440 / 1964$, tendo como objetivo a suplementação das despesas públicas com a educação elementar (ensino fundamental) [...] por meio do Decreto-Lei no 1.422/1975 e do Dec. 76.923/1975, novas alterações foram implantadas no contexto do Salário-Educação, passando sua alíquota a ser calculada à base de $2,5 \%$ do salário de contribuição das empresas, situação que perdura até os dias atuais. Disponível em http://www.fnde.gov.br/financiamento/salarioeducacao/salario-educacao-entendendo-o. Acesso em: 20/02/2017
} 
condições de manutenção e investimentos para o alcance das metas previstas no PNE.

Os dados foram organizados em tabelas e, posteriormente, analisados com apoio de estudos que buscam compreender a problemática do financiamento da educação brasileira a partir de uma perspectiva teórica crítica que busca estabelecer relações entre os resultados encontrados e seus condicionantes históricos, políticos, econômicos e sociais.

\section{RESULTADOS}

O papel da União no financiamento da educação segue o disposto no artigo 211 da Constituição Federal (1988),

§ 10 A União organizará o sistema federal de ensino e o dos Territórios, financiará as instituições de ensino públicas federais e exercerá, em matéria educacional, função redistributiva e supletiva, de forma a garantir equalização de oportunidades

educacionais e padrão mínimo de qualidade do ensino mediante assistência técnica e financeira aos Estados, ao Distrito Federal e aos Municípios; (grifo nosso).
Tendo por base a função da União no financiamento, podemos considerar que ela exerce função redistributiva e supletiva. Entretanto, nos estados e municípios, haverá ainda a função própria que corresponde à capacidade de arrecadação dos estados/municípios através dos impostos que não compõem a cesta do FUNDEB, assinalados assim como Recursos de Manutenção e Desenvolvimento do Ensino - MDE.

A função redistributiva refere-se, portanto, à redistribuição de recursos de forma horizontal, tendo por objetivo a equalização das oportunidades educacionais enquanto a função supletiva refere-se às ações para manutenção do equilíbrio federativo e, assim, à manutenção da educação básica por meio da suplementação de recursos financeiros em programas específicos. (MARTINS, 2016).

Dentro da função redistributiva, dois grandes recursos podem ser destacados, o FUNDEB e o Salário Educação e, portanto, as principais fontes de receitas dos municípios para o cumprimento das metas estabelecidas nos Planos Municipais de Educação.

Se estabelecermos uma comparação entre o comportamento de arrecadação do FUNDEB nos anos pós aprovação do PNE e ainda da evolução da inflação e do Piso Salarial Profissional Nacional, temos:

Tabela 1. Evolução do FUNDEB em comparação com o IPCA e PSPN

\begin{tabular}{|c|c|c|c|c|}
\hline $\begin{array}{l}\text { Ano } \quad-\quad \text { Pós } \\
\text { aprovação do PNE. }\end{array}$ & $\begin{array}{l}\text { V.A.A } A^{4}-\text { Ensino } \\
\text { Fundamental - } \\
\text { FUNDEB (Turno } \\
\text { Parcial) }\end{array}$ & $\begin{array}{l}\text { Variação em } \\
\text { comparação ao VAA - } \\
\text { FUNDEB do ano anterior }\end{array}$ & $\begin{array}{l}\text { INFLAÇÃO MÉDIA NO } \\
\text { ANO }\left(\text { IPCA }^{5}\right)\end{array}$ & $\begin{array}{llr}\text { PERCENTUAL } & \text { DE } \\
\text { AUMENTO DO PISO } \\
\text { SALARIAL PROFISSIONAL } \\
\text { NACIONAL (PSPN) } & { }^{6} \text { EM } \\
\text { RELAÇÃO AO } & \text { ANO } \\
\text { ANTERIOR } & & \\
\end{array}$ \\
\hline 2017 & $2.875,03$ & $4,94 \%$ & 4,50\% previsão & $7,64 \%$ \\
\hline 2016 & $2.739,77$ & $7,64 \%$ & $6,29 \%$ & $11,36 \%$ \\
\hline 2015 & $2.545,31$ & $-3,26 \%$ & $10,67 \%$ & $12,98 \%$ \\
\hline 2014 & $2.628,41$ & -- & -- & -- \\
\hline
\end{tabular}

Fonte: Tabela organizada pelos autores a partir de dados obtidos nos sítios do MEC, do FNDE e do IBGE.

\footnotetext{
${ }^{4}$ O FUNDEB estipula através da previsão de arrecadação de receitas um Valor Aluno Anual Mínimo - V.A.A, válido para todo o território nacional, mas que pode ser transposto de acordo com a capacidade de arrecadação de cada Estado, de modo que, diferentes estados, tenham diferentes V.A.A, quanto maior arrecadação, maior o V.A.A. Em caso da capacidade de arrecadação do estado não seja suficiente para compor o VAA mínimo, a União faz a complementação, garantindo que todos os Estados garantam um Valor mínimo a ser investido por aluno.

${ }^{5} \mathrm{O}$ Índice Nacional de Preços ao Consumidor Amplo - IPCA é um indicador do Instituto Brasileiro de Geografia e Estatística foi criado com o objetivo de oferecer a variação dos preços no comércio para o público final. O IPCA é considerado o índice oficial de inflação do país. (http://www.ibge.gov.br/home/estatistica/indicadores/precos/inpc ipca/defaultinpc.shtm) Acesso em 01/03/2017.

${ }^{6} \mathrm{Em} 16$ de julho de 2008 foi sancionada a Lei ${ }^{\circ} 11.738$, que instituiu o piso salarial profissional nacional para os profissionais do magistério público da educação básica..http://portal.mec.gov.br/piso-salarial-de-professores). Acesso em 01/03/2017.
} 
Neste sentido, se compararmos o Salário Educação com a evolução das matrículas
NA Educação Básica e, ainda, com o IPCA, podemos observar:

Tabela 2. Evolução do Salário Educação em Comparação com o Quantitativo de Matrículas e o IPCA

\begin{tabular}{l|l|l|l|l|r|r}
\hline Ano & $\begin{array}{l}\text { Estimativa de } \\
\text { Arrecadação } \\
\text { Educação (R\$) }\end{array}$ & $\begin{array}{l}\text { Variação } \\
\text { percentual do ano } \\
\text { anterior }\end{array}$ & $\begin{array}{l}\text { Número de } \\
\text { Matrículas na } \\
\text { Educação } \\
\text { Básica }\end{array}$ & $\begin{array}{l}\text { Evolução de } \\
\text { matrículas } \\
\text { (Percentual) }\end{array}$ & $\begin{array}{l}\text { Índice } \\
\text { Inflação } \\
\text { IPCA }\end{array}$ & de \\
\hline 2016 & $11.711 .908 .229,41$ & $-4,41 \%$ & 48.817 .479 & $0,04 \%$ & $6,29 \%$ \\
\hline 2015 & $12.252 .312 .344,98$ & $9,04 \%$ & 48.796 .512 & $-1,95 \%$ & $10,67 \%$ \\
\hline 2014 & $11.235 .868 .902,28$ & -- & 49.771 .371 & -- & -- \\
\hline
\end{tabular}

Fonte: Tabela criada a partir de dados obtidos nos sítios do INEP, do FNDE e do IBGE.

Ainda considerando o Salário Educação

podemos observar as seguintes alterações nas alíquotas em comparação aos anos de escolarização obrigatória:

Tabela 3. Evolução da Alíquota do Salário Educação:

\begin{tabular}{l|l|c}
\hline Ano & Escolarização Obrigatória & $\begin{array}{l}\text { Alíquota paga pelas empresas tendo por base o salário } \\
\text { de contribuição previdenciária de seus funcionários }\end{array}$ \\
\hline 1965 & 4 anos (Lei n.o 4.024/1961) & $1,4 \%$ \\
\hline 1975 & 8 anos (Lei n.o 5.692/1975) & $2,5 \%$ \\
\hline 2017 & $\begin{array}{l}\text { 14 anos (Lei n.o 9.394/96 alterada } \\
\text { pela Emenda Constitucional n.o } \\
59 / 2009)\end{array}$ & $2,5 \%$ \\
\hline
\end{tabular}

\section{DISCUSSÃO}

Na tabela 1, podemos observar que, mesmo após a aprovação do PNE, em 2014, e dos Planos Municipais de Educação, em 2015, não houve aumento do VAA, ao contrário, é perceptível uma queda neste valor, permitindonos concluir que o FUNDEB, por si só, não garantirá o cumprimento das metas constantes destes planejamentos, uma vez que, considerado o poder de compra dos sistemas de ensino com base na inflação anual (2015), o Fundo não garantiu sequer a manutenção, muito menos novos investimentos, já que perdeu mais de $13 \%$ (déficit do FUNDEB somado a Inflação) se comparado ao exercício anterior.

Se considerarmos o total de receitas acumulado no período 2015 - 2017 (atual), concluímos que o FUNDEB evolui cerca 12,5\%, mas contra o avanço de despesas pela inflação medida no período (IPCA) de $21,4 \%$ e, ainda, a evolução no PSPN no montante de $31,9 \%$. A constatação é que, considerando o FUNDEB, mesmo após a aprovação do PNE, não estão sendo garantidas condições de manutenção do ensino básico, tendo em vistas a perda do poder de aquisição demonstrado.

Sobre o Salário Educação, o sítio oficial do Fundo Nacional de Desenvolvimento da Educação - FNDE destaca,

Ao longo do tempo, não
só a alíquota de
recolhimento do salário-
educação sofreu
relevantes modificações,
mas também os critérios
de arrecadação, repartição
e distribuição dos recursos
gerados passaram por
aperfeiçoamentos
significativos.
(www.fnde.gov.br, grifo
nosso)

É importante destacar alguns pontos: o primeiro é que o Salário Educação é criado num contexto de acesso à educação como direito e obrigatoriedade somente no ensino primário de 4 anos (artigo 27, Lei 4.024/61), ampliado para o ensino obrigatório de 8 anos (artigo 20, Lei 5.692/71). Assim sendo, na criação do Salário 
Educação o ensino tinha duração de 4 anos e uma alíquota de 1,4\%, em 1975, como a oferta de ensino obrigatório era de 8 anos, a lógica do financiamento da QSE deveria ser de uma alíquota de $2,8 \%$, ou seja, o dobro do tempo de ensino, o dobro da alíquota, mas isso não ocorreu, e a atualização foi para $2,5 \%$, denotando uma perda de $0,3 \%$ nas receitas da educação pública. A desatualização da QSE se materializa ainda mais com a expansão do ensino, pois, nos termos da Emenda Constitucional 59/2009, a educação obrigatória inicia-se aos 4 até os 17 anos de idade, ou seja, 14 anos de escolarização, e os mesmos $2,5 \%$ de contribuição das empresas para com a responsabilidade social e educacional brasileira.

Neste contexto não é possível identificar o afirmado pelo FNDE e grifado na citação acima sobre as relevantes modificações nas alíquotas do Salário Educação, outrora sim, ratificar uma desatualização e uma prevaricação do Poder Público em maximizar sua capacidade de arrecadação ante às empresas.

Pela Tabela 2 é possível observar um outro entrave que se dá pela capacidade de arrecadação do Salário Educação, conforme pode ser observado pela tabela, após a aprovação dos Planos Municipais de Educação, a QSE teve uma queda de arrecadação no ano de 2016, em torno de $-4,63 \%$, o que significa cerca de $\mathrm{R} \$ 540.404 .115,57$ a menos de manutenção e investimentos na educação básica pública. Não obstante a isso, no mesmo período houve um aumento do atendimento escolar, que apesar de parecer um percentual baixo $(0,04 \%)$, consiste efetivamente em um aumento de 20.967 matrículas. O que se materializa então aos gestores é garantir condições de acesso e permanência nos bancos escolares, com a qualidade e os desafios educacionais constantes nos Planos de Educação, com um quantitativo maior de alunos, e menor aporte financeiro.

Uma outra comparação importante a ressaltar, e que consiste também num entrave educacional, é o avanço do índice inflacionário no período pós aprovação dos planos municipais de educação (2015-2016), pois, o aumento de preços ao consumidor final, significou $16,96 \%$, um claro aumento as despesas no setor público, principalmente no que concerne ao transporte e alimentação escolar, enquanto a QSE, no mesmo período, teve um avanço na arrecadação de receitas de apenas $4,63 \%$.

\section{CONCLUSÃO}

Embora definidas as funções da União em lei, ainda são latentes os sérios problemas referentes ao financiamento da educação. Podese destacar, como exemplo, o Custo Aluno Qualidade - CAQ que, apesar do reconhecimento de sua importância para a transposição dos limites do FUNDEB, das manifestações positivas do Conselho Nacional de Educação e de sua presença no PNE como estratégia a ser alcançada, ainda carece de regulação.

É notório afirmar que por si só, o FUNDEB e o Salário Educação, não farão a redenção da educação brasileira, nem mesmo garantindo a efetivação das metas e estratégias dos Planos de Educação, seja ele Nacional, ou em sua materialização como municipal, este fator se dá, principalmente, pela queda na capacidade de arrecadação de receitas que diminuem em épocas de crise, pela própria sonegação fiscal, pela corrupção, e ainda pela prevaricação do poder público na atualização de alíquotas como do salário educação (há 42 anos sem reajuste).

Pode-se concluir que sem uma nova política/reforma fiscal que, de fato, garanta novos recursos para a educação, o PNE/PME se tornarão apenas ferramentas de planejamento da ação organizacional, não chegando ao plano da ação, culminando num processo de apenas manutenção ou precarização do já oferecido pelas redes de ensino, não garantindo investimentos reais em Educação.

\section{REFERÊNCIAS}

BRASIL. Constituição (1988). Constituição [da] Republica Federativa do Brasil. Brasília, DF: Senado Federal. Disponível em: $<$ www.planalto.gov.br/ccivil 03/constituicao/con stituicao.htm>. Acesso em: 01 fev. 2017.

BRASIL. Lei 13.005 de 25 de junho de 2014. Aprova o Plano Nacional de Educação - PNE e dá outras providências. Brasília, DF. Disponível em: $<$ http://www.planalto.gov.br/ccivil 03/ ato20112014/2014/lei//13005.htm>. Acesso em: $01 \mathrm{fev}$. 2017.

BRASIL. Lei 4.024 de 20 de dezembro de 1961. Fixa as diretrizes e bases da educação nacional. Brasília, DF. Disponível em: $<$ http://www.planalto.gov.br/ccivil 03/leis/L4024 .htm>. Acesso em: 05 fev. 2017. 
BRASIL. Lei 5.692 de 11 de agosto de 1971. Fixa diretrizes e bases para o ensino de 10 e 20 graus, e dá outras providências. Brasília, DF. Disponível em:

<http://www.planalto.gov.br/ccivil 03/leis/L5692 .htm>. Acesso em: 05 fev. 2017.

MARTINS, P. de S. A construção do Sistema Nacional de Educação: a cooperação federativa e os desafios para o financiamento da educação. In: AMARAL, N. S., AGUIAR, M. A. de S. (Orgs.) Financiamento da Educação. Camaragibe/PE: CCS Gráfica, 2016.

OLIVEIRA, R. P. O financiamento da educação. In: In: OLIVEIRA, R. P.; ADRIÃO, T. (Orgs.). Gestão, financiamento e direito à educação: análise da constituição federal e da LDB. 3. ed. São Paulo: Xamã, 2007. p. 83-122.

Recebido para publicação em: 08/08/2017 Revisado em: 15/09/2017

Aceito em: 28/09/2017 